Supplement of Clim. Past, 15, 1113-1131, 2019

https://doi.org/10.5194/cp-15-1113-2019-supplement

(c) Author(s) 2019. This work is distributed under

the Creative Commons Attribution 4.0 License.

(c) (1)

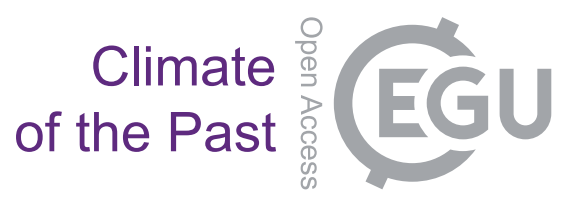

Supplement of

\title{
Early summer hydroclimatic signals are captured well by tree-ring earlywood width in the eastern Qinling Mountains, central China
}

Yesi Zhao et al.

Correspondence to: Jiangfeng Shi (shijf@nju.edu.cn)

The copyright of individual parts of the supplement might differ from the CC BY 4.0 License. 
Table S1. Correlation coefficients between the tree-ring width chronologies from the two study sites, Baiyunshan and Longchiman, over their common period 1850-2005.

\begin{tabular}{lccl}
\hline \multirow{2}{*}{ Chronologies } & \multicolumn{3}{c}{ Detrending method } \\
\cline { 2 - 4 } EWW STD & $0.63 / 0.59$ & SP67 & SPA50 \\
\hline LWW STD & $0.40 / 0.51$ & $0.64 / 0.60$ & $0.62 / 0.57$ \\
TRW STD & $0.58 / 0.58$ & $0.46 / 0.49$ & $0.46 / 0.47$ \\
EWW SSF & $0.64 / 0.60$ & $0.60 / 0.62$ & $0.61 / 0.63$ \\
LWW SSF & $0.43 / 0.54$ & $0.57 / 0.53$ & $0.55 / 0.49$ \\
TRW SSF & $0.57 / 0.57$ & $0.37 / 0.51$ & $0.35 / 0.47$ \\
\hline
\end{tabular}

Note: The correlation coefficients before (after) the slashes are for the original (prewhitened and linearly detrended) STD and SSF chronologies. All correlation coefficients are statistically significant at the 0.001 level based on Monte Carlo test (Efron and Tibshirani, 1986; Macias-Fauria et al., 2012). 
Table S2. Descriptive statitics of the composite STD and SSF tree-ring width chronologies when EPS $\geqslant 0.85$.

\begin{tabular}{cccccc}
\hline $\begin{array}{c}\text { Detrending } \\
\text { method }\end{array}$ & Chronology & $\begin{array}{c}\text { Starting year when } \\
\text { EPS } \geqslant 0.85\end{array}$ & $\begin{array}{c}\text { Standard } \\
\text { deviation }\end{array}$ & $\begin{array}{c}\text { Mean } \\
\text { sensitivity }\end{array}$ & $\begin{array}{c}\text { First-order } \\
\text { autocorrelation }\end{array}$ \\
\hline NELR & EWW STD & 1868 & 0.238 & 0.225 & 0.348 \\
& LWW STD & 1877 & 0.25 & 0.221 & 0.421 \\
& TRW STD & 1871 & 0.221 & 0.200 & 0.458 \\
SP67 & EWW STD & 1871 & 0.235 & 0.222 & 0.354 \\
& LWW STD & 1877 & 0.247 & 0.227 & 0.38 \\
& TRW STD & 1871 & 0.218 & 0.200 & 0.439 \\
SPA50 & EWW STD & 1867 & 0.234 & 0.223 & 0.328 \\
& LWW STD & 1875 & 0.245 & 0.225 & 0.384 \\
& TRW STD & 1866 & 0.215 & 0.200 & 0.42 \\
NELR & EWW SSF & 1868 & 0.245 & 0.226 & 0.382 \\
& LWW SSF & 1875 & 0.263 & 0.221 & 0.451 \\
& TRW SSF & 1868 & 0.227 & 0.200 & 0.479 \\
SP67 & EWW SSF & 1868 & 0.245 & 0.225 & 0.397 \\
& LWW SSF & 1875 & 0.255 & 0.226 & 0.404 \\
& TRW SSF & 1871 & 0.227 & 0.201 & 0.48 \\
SPA50 & EWW SSF & 1867 & 0.234 & 0.207 & 0.418 \\
& LWW SSF & 1875 & 0.246 & 0.214 & 0.426 \\
& TRW SSF & 1866 & 0.214 & 0.191 & 0.459 \\
\hline
\end{tabular}

Note: All statistics were calculated using the R package “dplR” version 1.6.9 (Bunn et al., 2018). 
Table S3. Statitics of the detrended ring-width series over their common period 1915-2005.

\begin{tabular}{cccccc}
\hline Detrending method & Chronology & Var $_{\text {pc1 }}$ & Rbar $_{\text {eff }}$ & SNR & EPS \\
\hline NELR & EWW STD & 0.386 & 0.443 & 25.878 & 0.963 \\
& LWW STD & 0.328 & 0.358 & 18.175 & 0.948 \\
SP67 & TRW STD & 0.384 & 0.433 & 24.806 & 0.961 \\
& EWW STD & 0.427 & 0.492 & 31.452 & 0.969 \\
& LWW STD & 0.353 & 0.400 & 21.702 & 0.956 \\
\multirow{2}{*}{ SPA50 } & TRW STD & 0.422 & 0.481 & 30.104 & 0.96 \\
& EWW STD & 0.411 & 0.471 & 29.007 & 0.967 \\
& LWW STD & 0.341 & 0.384 & 20.315 & 0.953 \\
\multirow{2}{*}{ NELR } & TRW STD & 0.404 & 0.459 & 27.607 & 0.965 \\
& EWW SSF & 0.399 & 0.456 & 27.291 & 0.965 \\
& LWW SSF & 0.317 & 0.346 & 17.252 & 0.945 \\
& TRW SSF & 0.393 & 0.439 & 25.492 & 0.962 \\
SP67 & EWW SSF & 0.453 & 0.520 & 35.298 & 0.972 \\
& LWW SSF & 0.366 & 0.417 & 23.308 & 0.959 \\
& TRW SSF & 0.441 & 0.504 & 33.033 & 0.971 \\
& EWW SSF & 0.474 & 0.539 & 37.994 & 0.974 \\
& LWW SSF & 0.352 & 0.399 & 21.627 & 0.956 \\
& TRW SSF & 0.431 & 0.491 & 31.354 & 0.969 \\
\hline
\end{tabular}

Note: The common period for the tree-ring width dataset was calculated with the "common.interval" function in R package "dplR" version 1.6.9 (Bunn et al., 2018) based on a trade-off between the maximum number of series and years. The statistics, $\operatorname{Var}_{\mathrm{pc} 1}, \mathrm{Rbar}_{\mathrm{eff}}, \mathrm{SNR}$, and EPS represent the variance explained by the first eigenvector, effective chronology signal, signal-to-noise ratio, and expressed population signal, respectively. The $\operatorname{Var}_{\mathrm{pc} 1}$ was calculated using the Program ARSTAN40c (Cook and Krusic, 2006), and the other statistics were calculated using the R package "dplR” version 1.6.9 (Bunn et al., 2018). 
Table S4. The meterological stations utilized by CRU dataset (http://www.cru.uea.ac.uk/data) located in the area between latitudes $32^{\circ} \mathrm{N}$ and $34.5^{\circ} \mathrm{N}$, and longitudes $111^{\circ} \mathrm{E}$ and $112^{\circ} \mathrm{E}$.

\begin{tabular}{lllll}
\hline $\begin{array}{l}\text { Meteorological } \\
\text { station }\end{array}$ & $\begin{array}{l}\text { Longitude } \\
\left({ }^{\circ} \mathrm{E}\right)\end{array}$ & $\begin{array}{l}\text { Latitude } \\
\left({ }^{\circ} \mathrm{N}\right)\end{array}$ & Climatic factor & Temporal cover \\
\hline Lushi & 111.03 & 34.05 & $\begin{array}{l}\text { Precipitation } \\
\text { Temperature }\end{array}$ & $1952.07-2013.12$ \\
& & & $1952.07-2016.12$ \\
Laohekou & \multirow{2}{*}{11.73} & \multirow{2}{*}{32.43} & Precipitation & $1933.02-1933.11 ; 1934.01-$ \\
& & & $1935.06 ; 1935.08-1935.12 ;$ \\
& & & & $1936.08-1938.07 ; 1950.06-$ \\
& & & & $2005.06 ; 2005.08-2013.12$ \\
Yunxian & \multirow{2}{*}{32.9} & Pemperature & $1951.01-2016.12$ \\
& & & & $1933.03-1938.05 ; 1938.07-$ \\
& & & & $1947.10 ; 1950.03-1990.12 ;$ \\
\end{tabular}


Table S5. The reconstructed May-July (MJJ) scPDSI during the period 1868-2005.

\begin{tabular}{|c|c|c|c|c|c|c|c|}
\hline Year & scPDSI & Year & scPDSI & Year & scPDSI & Year & scPDSI \\
\hline 1868 & -1.427 & 1904 & 1.167 & 1940 & -1.139 & 1976 & -1.394 \\
\hline 1869 & 2.307 & 1905 & 2.260 & 1941 & -1.300 & 1977 & -1.474 \\
\hline 1870 & -0.388 & 1906 & 3.654 & 1942 & 0.859 & 1978 & -1.829 \\
\hline 1871 & -0.321 & 1907 & -0.630 & 1943 & 1.046 & 1979 & -0.046 \\
\hline 1872 & -0.227 & 1908 & -0.080 & 1944 & 2.380 & 1980 & 2.065 \\
\hline 1873 & -0.918 & 1909 & -0.777 & 1945 & -0.656 & 1981 & 0.088 \\
\hline 1874 & -1.682 & 1910 & 2.045 & 1946 & 1.589 & 1982 & 0.859 \\
\hline 1875 & -1.374 & 1911 & 3.842 & 1947 & 0.986 & 1983 & 4.150 \\
\hline 1876 & 0.564 & 1912 & 2.012 & 1948 & 2.809 & 1984 & 2.327 \\
\hline 1877 & -1.568 & 1913 & -0.495 & 1949 & 2.950 & 1985 & 1.891 \\
\hline 1878 & 0.570 & 1914 & -0.006 & 1950 & 1.998 & 1986 & -0.770 \\
\hline 1879 & -3.612 & 1915 & 0.939 & 1951 & 1.428 & 1987 & 1.851 \\
\hline 1880 & -1.984 & 1916 & -0.636 & 1952 & 1.549 & 1988 & -0.127 \\
\hline 1881 & -0.991 & 1917 & -1.179 & 1953 & 1.160 & 1989 & 0.269 \\
\hline 1882 & 1.958 & 1918 & -0.710 & 1954 & 1.355 & 1990 & 2.320 \\
\hline 1883 & 2.622 & 1919 & -0.167 & 1955 & -1.682 & 1991 & 1.194 \\
\hline 1884 & 1.254 & 1920 & -1.749 & 1956 & 1.415 & 1992 & -0.991 \\
\hline 1885 & 3.071 & 1921 & 0.497 & 1957 & 0.356 & 1993 & 1.288 \\
\hline 1886 & 1.522 & 1922 & 0.758 & 1958 & 0.550 & 1994 & -2.118 \\
\hline 1887 & 1.321 & 1923 & -2.279 & 1959 & 0.523 & 1995 & -2.104 \\
\hline 1888 & 0.624 & 1924 & -1.072 & 1960 & -0.107 & 1996 & 0.041 \\
\hline 1889 & 1.254 & 1925 & 0.255 & 1961 & -0.247 & 1997 & -0.556 \\
\hline 1890 & 0.624 & 1926 & -2.325 & 1962 & 0.517 & 1998 & 1.341 \\
\hline 1891 & -1.441 & 1927 & -0.341 & 1963 & 0.336 & 1999 & 0.115 \\
\hline 1892 & -0.743 & 1928 & -1.782 & 1964 & 1.616 & 2000 & -2.942 \\
\hline 1893 & 1.462 & 1929 & -2.527 & 1965 & -0.241 & 2001 & -1.963 \\
\hline 1894 & 3.057 & 1930 & 1.931 & 1966 & 0.229 & 2002 & 0.289 \\
\hline 1895 & 2.112 & 1931 & 1.495 & 1967 & 0.262 & 2003 & 0.624 \\
\hline 1896 & 1.549 & 1932 & -0.569 & 1968 & -1.568 & 2004 & 0.517 \\
\hline 1897 & 1.120 & 1933 & 2.514 & 1969 & -0.878 & 2005 & 1.777 \\
\hline 1898 & 3.768 & 1934 & 3.111 & 1970 & 1.355 & & \\
\hline 1899 & -1.025 & 1935 & 0.523 & 1971 & 1.777 & & \\
\hline 1900 & -2.238 & 1936 & 3.721 & 1972 & 0.839 & & \\
\hline 1901 & -0.489 & 1937 & 0.423 & 1973 & 2.970 & & \\
\hline 1902 & -1.923 & 1938 & 0.249 & 1974 & 1.428 & & \\
\hline 1903 & 0.544 & 1939 & -1.018 & 1975 & 1.020 & & \\
\hline
\end{tabular}




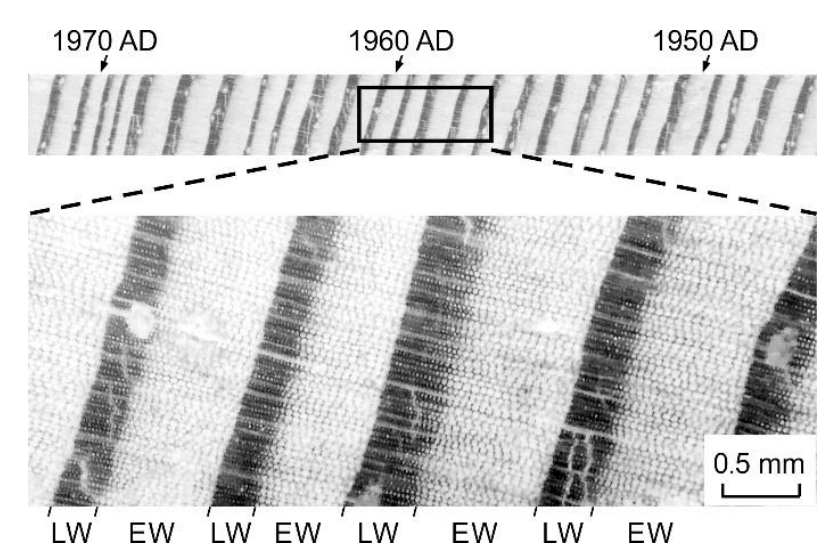

Figure S1. Photograph of a section of a P. tabulaeformis tree-ring sample (LCM0118A). The distinct earlywood (EW) and latewood (LW) segments can be identified by inspection under a microscope. 

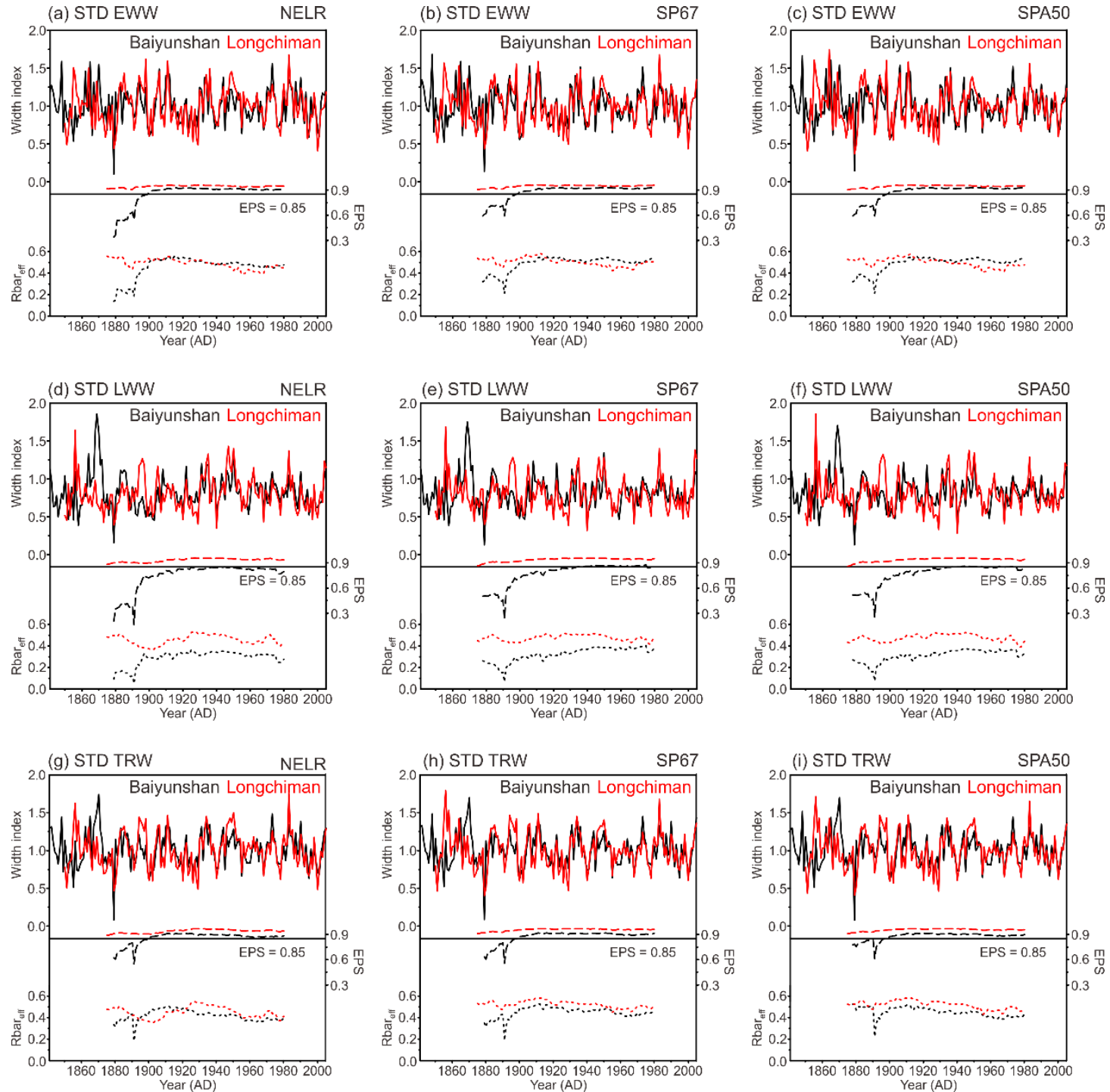

Figure S2. Standard (STD) tree-ring width chronologies (solid curves) generatued using different detrending methods for (a-c) earlywood width (EWW), (d-f) latewood width (LWW), and (g-i) total tree-ring width (TRW) at the two study sites, Baiyunshan (black) and Longchiman (red). The detrending methods are: (1) negative exponential functions combined with linear regression with negative (or zero) slope (NELR), (2) cubic smoothing splines with a $50 \%$ frequency cutoff at $67 \%$ of the series length (SP67), and (3) age-dependent splines with an initial stiffness of 50 years (SPA50). The dashed and dotted curves denote the running expressed population signal (EPS) and effective chronology signal $\left(\mathrm{Rbar}_{\text {eff }}\right)$, respectively. The horizontal line indicates the threshold EPS value of 0.85 . The running EPS and $\mathrm{Rbar}_{\text {eff }}$ values were calculated over a 51-year window. 

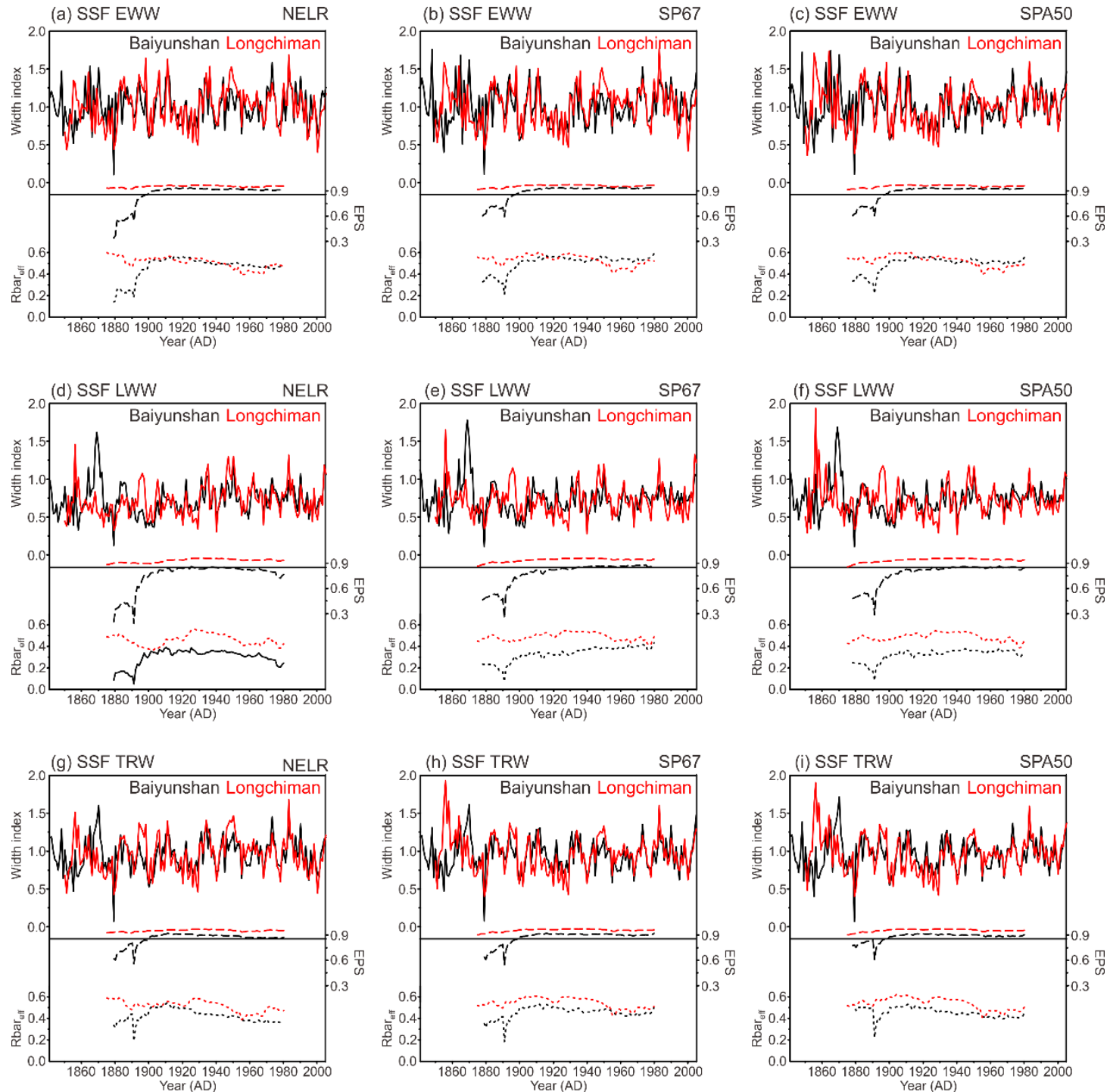

Figure S3. Signal-free (SSF) tree-ring width chronologies (solid curves) generatued using different detrending methods for (a-c) earlywood width (EWW), (d-f) latewood width (LWW), and (g-i) total tree-ring width (TRW) at the two study sites, Baiyunshan (black) and Longchiman (red). The detrending methods are: (1) negative exponential functions combined with linear regression with negative (or zero) slope (NELR), (2) cubic smoothing splines with a $50 \%$ frequency cutoff at $67 \%$ of the series length (SP67), and (3) age-dependent splines with an initial stiffness of 50 years (SPA50). The dashed and dotted curves denote the running expressed population signal (EPS) and effective chronology signal (Rbar $\left.{ }_{\text {eff }}\right)$, respectively. The horizontal line indicates the threshold EPS value of 0.85 . The running EPS and $\mathrm{Rbar}_{\text {eff }}$ values were calculated over a 51-year window. 

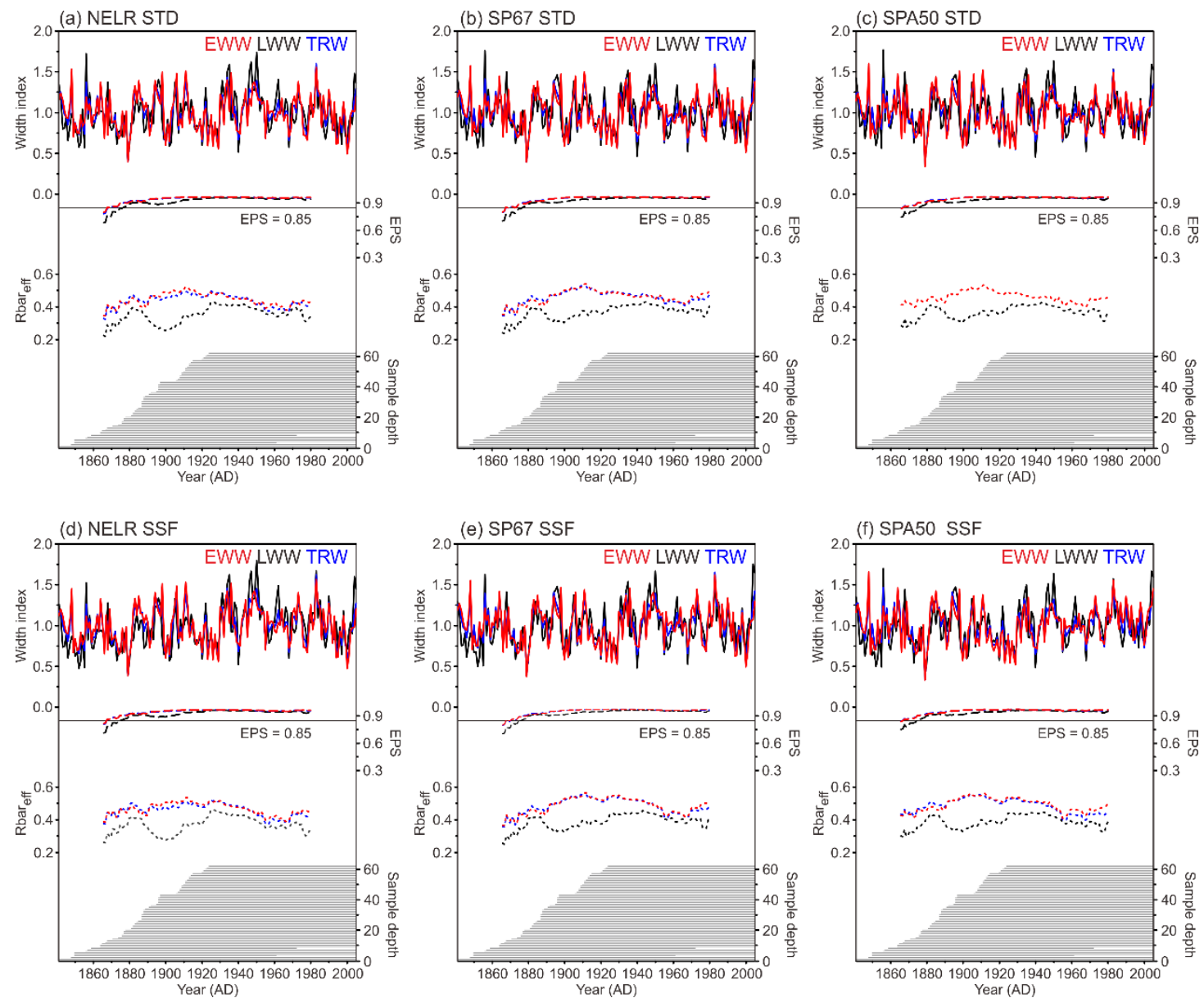

Figure S4. Composite (a-c) STD and (d-f) SSF tree-ring width chronologies for EWW (red), LWW (black), and TRW (blue) generated using the merged tree-ring samples from the two study sites, Baiyunshan and Longchiman, based on different detrending methods. The detrending methods are: (1) negative exponential functions combined with linear regression with negative (or zero) slope (NELR), (2) cubic smoothing splines with a $50 \%$ frequency cutoff at $67 \%$ of the series length (SP67), and (3) age-dependent splines with an initial stiffness of 50 years (SPA50). The dashed and dotted curves denote the running expressed population signal (EPS) and effective chronology signal ( Rbar $_{\text {eff }}$ ), respectively. The horizontal line indicates the threshold EPS value of 0.85 . The running EPS and Rbar $r_{\text {eff }}$ values were calculated over a 51-year window. The segement plot indicates the sample depth (core). 


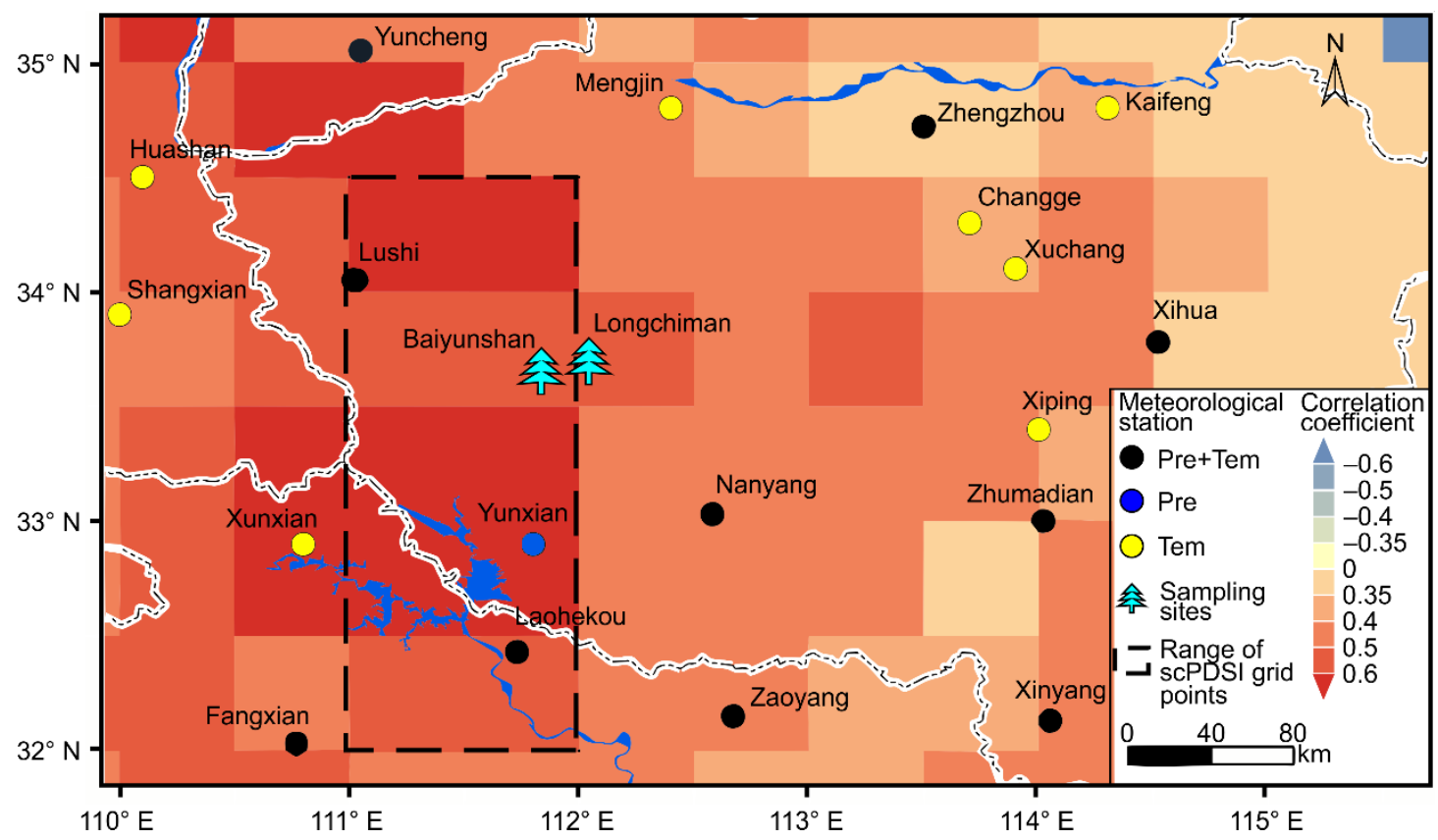

Figure S5. Spatial distribution of the meteorological stations included in the CRU dataset (http://www.cru.uea.ac.uk/data) around the tree-ring sampling sites, Baiyunshan and Longchiman. Black cycles represent the meteorological stations that provide both precipitation and temperature data. While, Blue (yellow) cycles represent those that only provide precipitation (temperature) data. The dashed rectangle indicates the range of scPDSI grid points used for calibration in this study. The color patches denote the spatial correlation coefficients between May-July scPDSI and NELR based EWW STD chronology. 


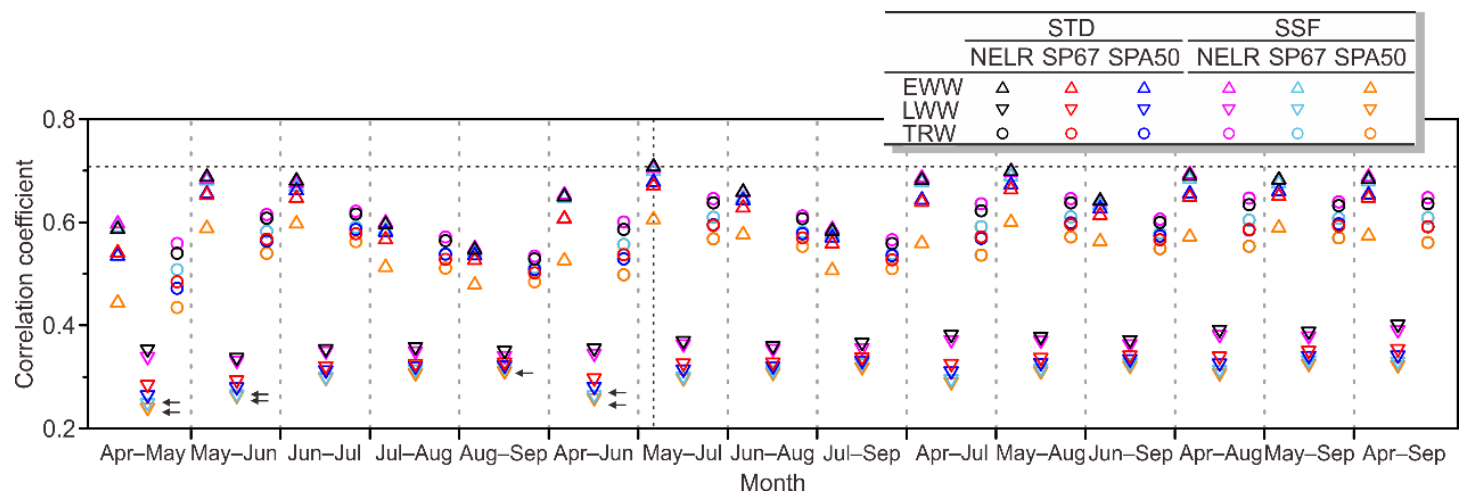

Figure S6. Correlation coefficients between the tree-ring width chronologies and multi-month averaged scPDSI (April to September of the current year). Upward triangles, downward triangles, and circles indicate the chronologies of EWW, LWW, and TRW, respectively. The color black, red and blue indicate the STD chronologies generated using the detrending methods NELR, SP67, and SPA50, while color magenta, cyan, and orange indicate the SSF chronologies generated using the detrending methods NELR, SP67, and SPA50, respectively. The arrow indicates that the corresponding correlation does not reach the 0.05 significance level, which was tested using the Monte Carlo method (Efron and Tibshirani, 1986; Macias-Fauria et al., 2012). 


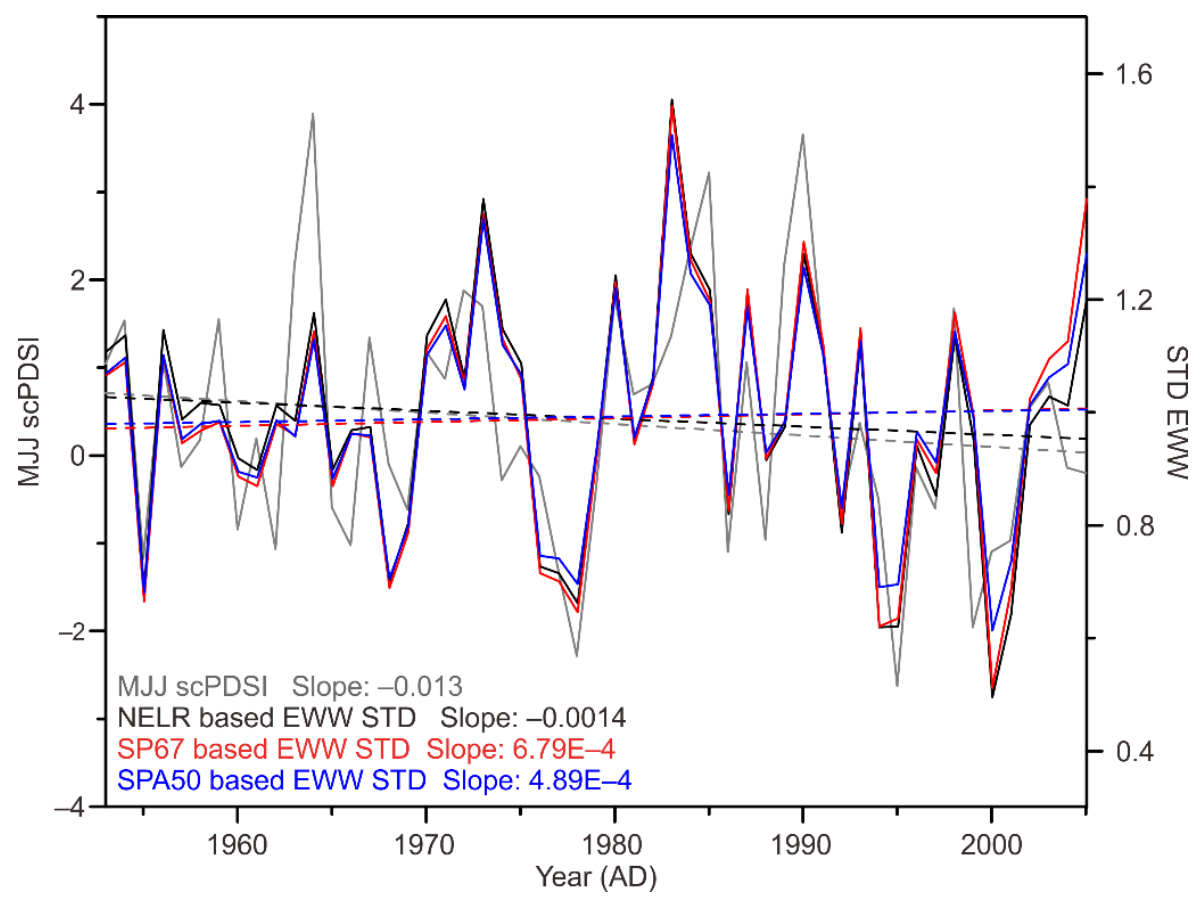

Figure S7. Comparisons between the MJJ scPDSI (gray) and EWW STD chronologies generated using the detrending methods NELR (black), SP67 (red), and SPA50 (blue) during the period 1953-2005. The dashed lines represent the linear trends. The slope coefficients are presented in the bottom left corner of the figure. 


\section{References}

Bunn, A., Korpela, M., Biondi, F., Campelo, F., Mérian, P., Qeadan, F., Zang, C., Pucha-Cofrep, D., and Wernicke, J.: dplR: Dendrochronology Program Library in R, https://CRAN.Rproject.org/packages=dplR, $\mathrm{r}$ package version 1.6.9, 2018.

Cook E.R., Krusic P.J.: ARSTAN 41: a tree-ring standardization program based on detrending and autoregressive time series modeling, with interactive graphics, Tree-Ring Laboratory, Lamont Doherty Earth Observatory of Columbia University, New York, 2006.

Efron, B., and Tibshirani, R.: Bootstrap methods for standard errors, confidence intervals, and other measures of statistical accuracy, Stat. Sci., 1, 54-75, https://www.jstor.org/stable/2245500, 1986.

Macias-Fauria, M., Grinsted, A., Helama, S., and Holopainen, J.: Persistence matters: Estimation of the statistical significance of paleoclimatic reconstruction statistics from autocorrelated time series, Dendrochronologia, 30, 179-187, https://doi.org/10.1016/j.dendro.2011.08.003, 2012. 